\title{
Evaluation of the effect of land vegetation cover on water and energy balance of an unsaturated pyroclastic cover
}

\author{
Alfredo Reder ${ }^{1,2 a}$, Guido Rianna ${ }^{2}$ and Luca Pagano ${ }^{1}$ \\ ${ }^{1}$ DICEA (Dipartimento di Ingegneria Civile, Edile e Ambientale), University "Federico II", via Claudio 21, 80123, Naples (Italy) \\ ${ }^{2}$ REMHI(Regional Models and geo Hydrological Impacts), CMCC, via Maiorise, Capua (Italy)
}

\begin{abstract}
Land cover features can strongly affect the actual soil wetting state; for example, the presence of a vegetated cover can induce relevant variations in the main components of soil-atmosphere water balance: interception and evapotranspiration. For these reasons, its proper characterization represents a crucial point in typical geotechnical issues as, for example, the assessment of slope stability conditions. To this aim, in the work, in two different hydrological year albeit characterized by comparable weather patterns, the variations induced by varying land cover have been investigated for water and heat balance of a soil volume constituted by pyroclastic soil. These soils, mantling a large part of slopes in Campania Region, are particularly interesting since they have been often affected, in last years, by landslide phenomena causing huge damages and victims. Observations are retrieved by a physical model constituted by a soil layer exposed to weather forcing and instrumented to record weather variables, component of soil surface heat balance and soil state properties within the layer. The two antipodal considered land cover conditions are bare soil and full natural vegetation (mixing of Lolium perenne, Festuca rubra and Poa pratensis); on Campania slopes, the first condition can be retrieved on slopes in man-modified areas (road cuts, quarries) while the second ones are plant species commonly found on Mediterranean slopes. The analysis focused on Summer season where in clearer way, different behaviour can be detected stressing the variations induced by the vegetation cover not only on the potential evaporative demand but also on the actual values.
\end{abstract}

\section{Introduction}

As well known, frequency, magnitude and consequences of rainfall induced landslides are highly related to the land use (and then the land cover) of the affected areas [1]. Land use, in fact, can directly influence the dynamics inducing an event by increasing or decreasing slope stability.

Concerning vegetated surfaces, Sidle \& Ochiai [1] recognize four mechanisms as the main hydrological effects for shallow landslides recognizing:

1) rainfall and snow are intercepted by canopies and they can directly evaporate from them inducing subsequent reduction of infiltration rates;

2) root systems extract water from soil via transpiration, leading to lower average soil moisture levels;

3 ) roots, stems and organic litter increase ground surface roughness and hydraulic conductivity in the shallower soil layers;

4) reduction of soil moisture may cause desiccation cracks, resulting in higher infiltration capacity and shortcircuiting of infiltrating water to a deeper failure plane.

The Authors state that the first two mechanisms result beneficial for the slope stability whereas the second two ones can be assumed marginally adverse.
Actually, a vegetation cover can be due to presence of natural vegetation, agricultural activities, pastureland, coppice or high forest: then beyond the general benefits/disadvantages above reported, the management and maintenance activities carried out in such contexts play a key role: proper clearcutting cycles for forested areas, conversion from natural vegetation to agricultural lands or grazed lands (more frequent in developing countries) or abandonment of agricultural activities no longer profitable (frequent in developed countries) can lead to substantial variations of associated maintenance activities. In this perspective, quantifying how the presence of a vegetated surface can influence the soil water balance and the water distribution within the soil (and then slope stability) in a specific geomorphological context represents a crucial issue. It is important also to properly assess the consequences of different options in land use planning. In this regard, for example, in recent years, the adoption of "green infrastructures" as mitigation tool for reducing the occurrence of landslide events or as adaptation countermeasure to cope with the effect of potential climate change have aroused a growing interest [2].

In this work, the effect of a vegetated surface overlying a pyroclastic soil layer has been investigated; in the specific, a comparison between the behaviour of a soil

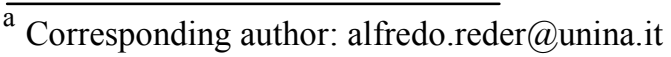


layer exposed to the atmosphere respectively in bare and vegetated surface conditions has been carried out.

It has been performed for the same season (JJA) in two different years characterized by comparable weather forcing; the attention focused mainly on variations induced by vegetation in evaporative losses.

The investigated layer is of particular interest since coming from slopes of Campania Region (Southern Italy), frequently affected in recent years, by landslide events able to induce huge economic damages and fatalities [3].

In effect, a large part of slopes in the region is covered by ashes and pumices produced by several eruptions of the two volcanic centres in the Region, Campi Flegrei and Somma Vesuvius [4]. The formed covers lie in partially saturated conditions continuously modified by the water exchanges between atmosphere and soil surface. These water exchanges affect the degree of saturation and then suction within the soil, entailing in reduction or increasing in the slope stability [5-8]. Suction drops following heavy/prolonged rainfalls can induce reductions of soil resistance until attaining failure conditions.

In last years, researchers have focused their activities mainly on quantifying the variations of suction due to precipitation events through laboratory and field studies [9-10]. Only recently the role of soil wetting state at the beginning of potential triggering event have been recognized as relevant for these events. Back analysis of the events occurred on Lattari Mts. (Gragnano and Pozzano, 1997; Nocera Inferiore, 2005) have pointed out the role of antecedent rainfall as predisposing conditions over a time periods also several months long [5,7,11-13]. On these intervals, however, not only wetting events but also evaporative losses (low but persisting outward flows) have a significant influence in determining the predisposing conditions.

Regarding Campanian pyroclastic covers, some studies have been conducted focusing on the effects of soil evaporation under bare soil conditions [14-18]; while the effects of plant transpiration have been scarcely investigated [19-21].

The experimentation of the present paper has been conducted over the hydrological period 2010-2014 under bare soil conditions, while since September 2015 the soil surface is covered with a full natural vegetation commonly found on Mediterranean slopes.

The paper initially describes the physical model, its monitoring instrumentation and the two different cover systems (\$2). Subsequently it displays the different evaporative patterns and interprets their trends (\$3.1). After the work shows some difference in terms of radiation fluxes between the two different cover systems trying to quantify the albedo values $(\$ 3.2)$. Finally, it highlights the effects of the different evaporative patterns in terms of water content $(\S 3.3)$.

\section{Physical model and investigated soil}

The monitoring activity has been performed on a layer contained in a wooden tank (surface area $=1.15 \times 1.15$ $\mathrm{m}$; thickness $=0.75 \mathrm{~m}$ ) (Figure 1$)$. The layer is a nonplastic silty sand (Figure 1a) taken from the stratigraphic series of Monteforte Irpino and widely characterized in its physical properties, mechanical and field hydrological behaviour [8,10,22]. Moreover, it displays consistent similarities with ashes mantling slopes of Nocera Inferiore area affected by failure events in last years [5]. The stratum has been deposed through dry pluviation technique [23] ensuring high porosity (about 70\%) close to that in situ.
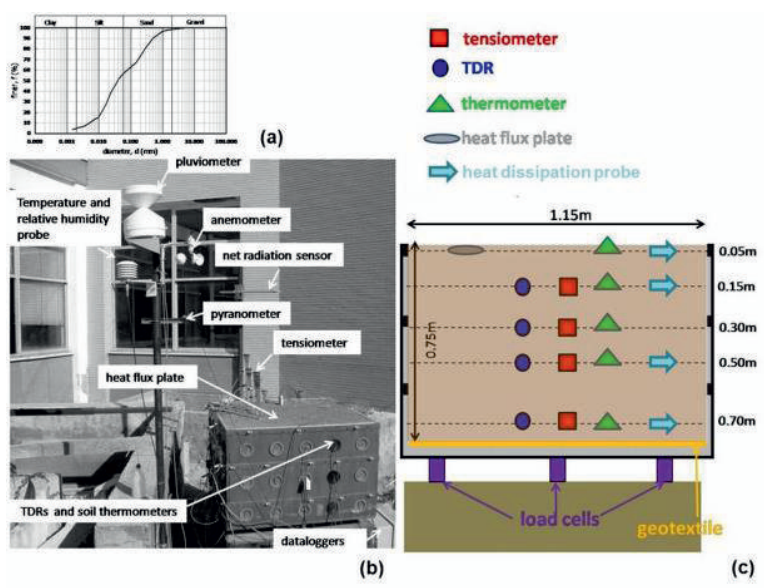

Figure 1. (a) Grain-size distribution of the soil layer; (b) picture of the physical model and of its devices; (c) monitoring devices installed within the soil layer (modified from [14] and [17]).

The monitoring system (Figure 1c) is conceived to quantify water and energy fluxes and the effects of such ones within the layer. Changes in water storage are monitored through three shear load cells; suction, water content and temperature within the soil are measured at 5 depths respectively using tensiometers $(0-70 \mathrm{kPa}) /$ heat dissipation probes $(15-500 \mathrm{kPa})$ [16-24], TDR probes and thermistors. Finally, a well-equipped weather station (Figure 1b) provides observations related to main meteorological variables (precipitation, air temperature, wind speed, humidity, air pressure) and main energetic components (net/solar radiation, soil heat flux).

The soil surface has been monitored in both bare (Figure $2 a)$ and vegetated conditions (Figure $2 b$ ).
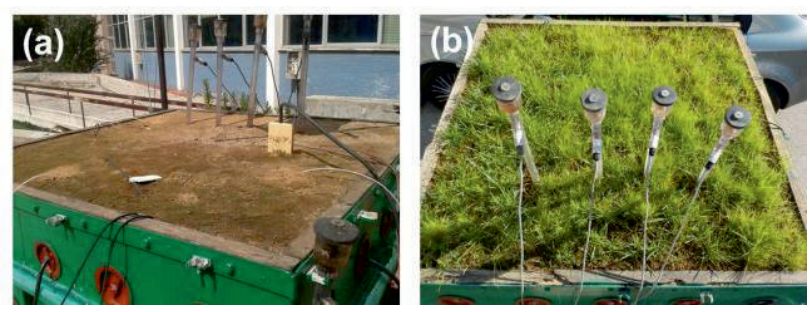

Figure 2. (a) Bare soil surface; (b) vegetated soil surface.

In the first phase, albeit not matching all the usual conditions met on site, the bare soil surface allowed investigating in simplified condition the effect of the soil evaporation.

After four years, a vegetation cover, constituted by a mixing of Lolium perenne, Festuca rubra and Poa pratensis has been planted.

The comparison between the monitoring data obtained under bare soil and vegetated conditions permits to 
illustrate and roughly discriminate the effects of plant transpiration on soil surface water balance and on state conditions within the layer.

\section{Evaluation of evaporative processes for different land cover conditions}

\subsection{Water balance}

During the five years of hydrological monitoring, the layer was subjected to natural sequences of precipitation and evaporation. This allowed the characterization of the soil hydrological response under different weather conditions and for different levels of suction and water content.

Hydrological behaviours observed under bare and vegetated conditions may be obviously be compared only if evaporative processes have been driven in the two cases by similar weather forcing and same initial soil states in terms of water content values.

Among the several sequences recorded during the four years of observation in bare conditions, the period ranging from $6^{\text {th }}$ June to $31^{\text {th }}$ August of the first hydrological year was selected. It resulted, in fact, the most similar in weather forcing and initial soil state to the corresponding period (falling in the fifth hydrological year) with vegetated cover.
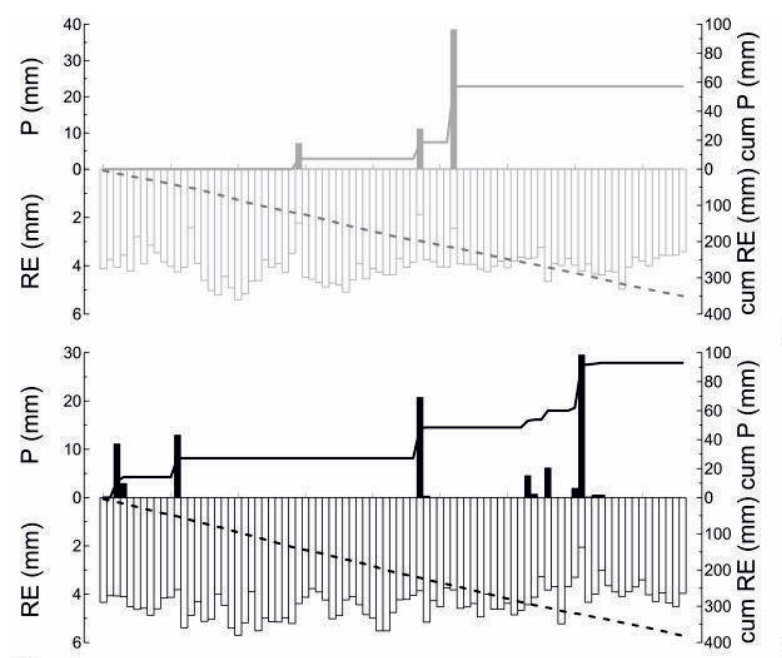

(a)

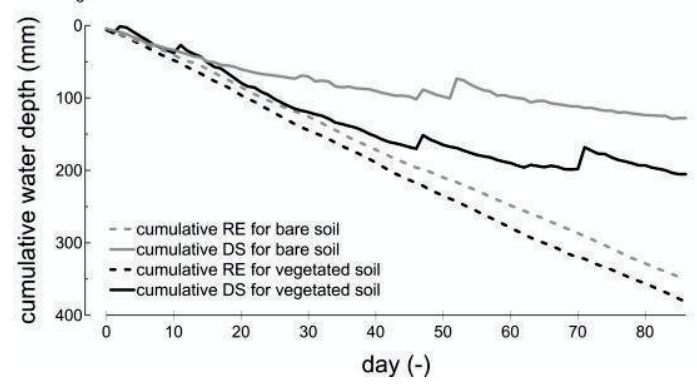

(b)

Figure 3. Daily and cumulative precipitation (P) and daily and cumulative reference evaporation (RE) for bare (a) and vegetated soil cover conditions (b); trends of cumulative reference evaporation and of cumulative water storage variations (DS - positive values correspond to water loses) for bare and vegetated soil cover conditions (c).
Firstly, the weather observations retrieved during this time window for bare soil and vegetated cover have been compared in order to assess the weather likeness of the two investigated periods. Specifically, daily and cumulative precipitation (P) and daily and cumulative reference evaporation (RE) [25] are displayed for the bare soil in Figure $3 \mathrm{a}$ and for the vegetated cover in Figure $3 \mathrm{~b}$ (the time instant $\mathrm{t}=0$ day corresponds to $6^{\text {th }}$ June and the time window lasts 86 days).

Reference Evaporation (RE) is used instead of Potential Evaporation (PE), according to Allen et al. [25]:

$$
R E=\frac{0.408 \Delta\left(R_{n}-G\right)+\gamma \frac{900}{T+273} u_{2}\left(e_{s}-e_{a}\right)}{\Delta+\gamma\left(1+0.34 u_{2}\right)}
$$

where:

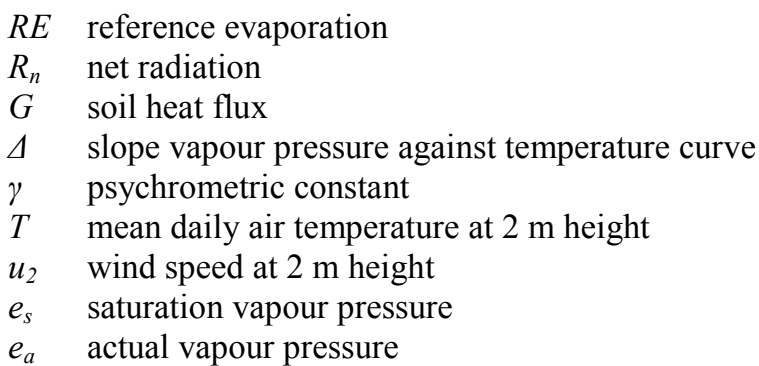

The reference evaporation takes into account, on the one hand, the role of available energy at the soil surface provided in terms of net radiation and soil heat flux and, on the other hand, the drying power associated to air movement depending on mean air temperature, relative humidity and wind speed.

During the investigated time windows, the evaporative demand estimated during the fifth year $(380.5 \mathrm{~mm})$ is higher than that estimated during the first year $(350.3$ $\mathrm{mm})$. On the same way, the total precipitation recorded during the fifth year $(93 \mathrm{~mm})$ is higher than that collected during the first year $(57.2 \mathrm{~mm})$.

At $\mathrm{t}=0$ the layer water storage is for the bare soil equal to $326 \mathrm{~mm}$, corresponding to an average volumetric water content $\theta=0.434$ whereas for the vegetated cover it is equal to $330 \mathrm{~mm}$, corresponding to an average volumetric water content $\theta=0.440$.

Figure $3 \mathrm{c}$ displays for both cases the trends of cumulative reference evaporation and the trends of cumulative water storage variations (DS).

Worth noting is that at the end of the reference period the spread between the two cases is in reference evaporation $(30.2 \mathrm{~mm})$ below the half that in water storage $(77 \mathrm{~mm})$. The layer in fact reduces its weight of $128 \mathrm{~mm}$ under bare soil conditions and of $205 \mathrm{~mm}$ under vegetated soil conditions.

In bare soil conditions cumulative reference evaporation departs from cumulative water storage at the beginning. The two trends are observed parallel only over few days following rainy events.

In vegetated soil conditions, however, cumulative water storage follows the cumulative reference evaporation for about 30 days. Subsequently, the two trends diverge. 
Even for this case the two curves return parallel over few days following precipitation events.

To better quantify the effect of plant transpiration, the trends of cumulative water storages have been cleaned of variations due to precipitation. This correction corresponds to eliminate the effects of precipitation on evaporation, consisting in the attainment of the potential value over few days.

Figure 4 compares the two cleaned curves.

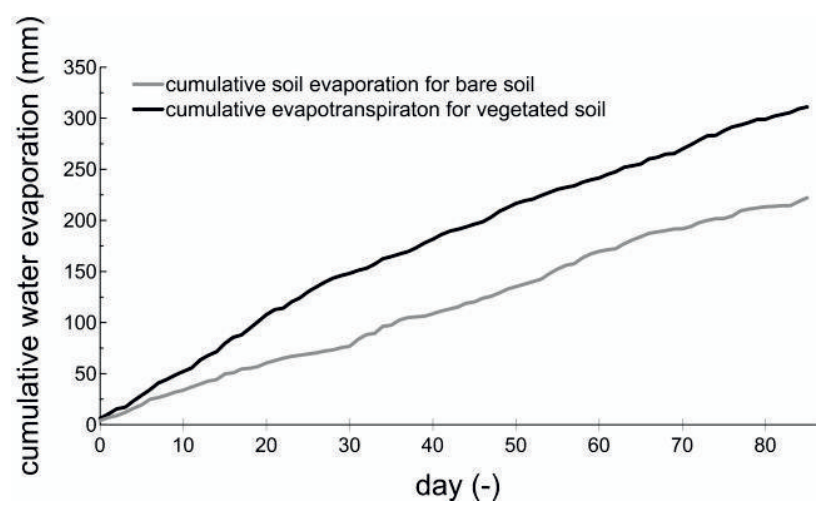

Figure 4. Trends of cumulative evaporation for bare and vegetated cover

Evaporation cumulating in bare conditions $(222 \mathrm{~mm})$ is much less than that cumulating in vegetated conditions (306 mm). The effect of plant transpiration may be obtained by computing the difference (306-222) and subtracting either the difference between reference evaporation values $(30 \mathrm{~mm})$. It can be stated that the presence of vegetation induces a reduction in total water storage equal to $54 \mathrm{~mm}$ (on average, $1 \mathrm{~mm} /$ day).

\subsection{Energy balance}

The difference in reference evaporations $(30 \mathrm{~mm})$ cumulating in the two cases at the end of the reference period may be itself related to differences in surface characteristics and consequent differences in available energies.

To this aim, Figure 5 shows the trends of cumulative energetic fluxes acting just above the soil surface during the investigated time window for the two cases. These fluxes are related to each other through the radiation balance that states the energy available at the soil surface (or net radiation) $R_{n}$ in the following way:

$$
R_{n}=(1-a) R_{s}-R_{n l}
$$

where:

$\begin{array}{ll}R_{n} & \text { net radiation } \\ R_{S} & \text { solar radiation } \\ R_{n l} & \text { net longwave radiation } \\ a & \text { albedo }\end{array}$

Through the weather station placed near to the layer, solar and net radiation can be directly measured; on the other hand, the net longwave radiation can be assessed by adopting the empirical relationship proposed by Allen et al [25]. It requires, as inputs, air temperature, relative humidity and cloudiness; these variables are provided by the weather station. In this way, the only unknown of (2) is the albedo. The albedo is a dimensionless coefficient that measures the reflectivity of an incident light depending on roughness, colour and inclination of the soil surface. It represents an important indicator for investigating the evaporative processes since it could influence the energy available at the soil surface and then could affect the evaporative demand.

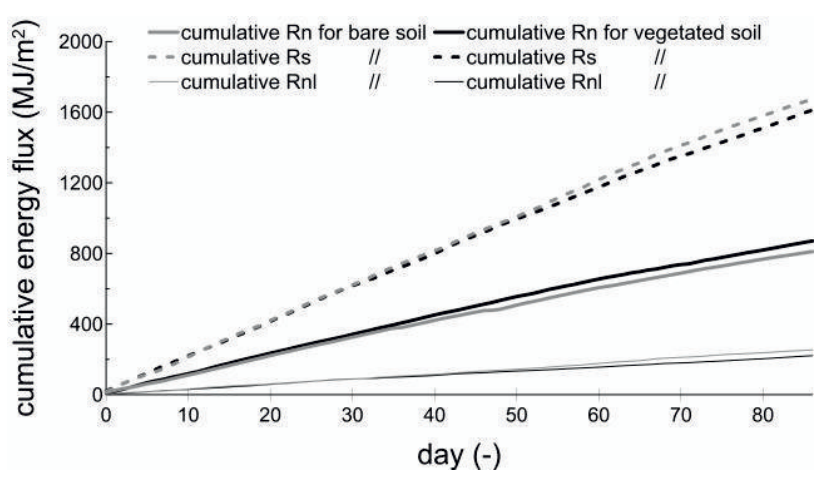

Figure 5. Trends of cumulative net radiation (Rn), solar radiation (Rs) and net longwave radiation ( $\mathrm{Rnl}$ ) quantified under bare and vegetated condition.

The energy provided by the sun during the entire monitoring time span under bare soil condition is slightly greater than that measured under vegetated condition $\left(1675 \mathrm{MJ} / \mathrm{m}^{2}\right.$ against $\left.1611 \mathrm{MJ} / \mathrm{m}^{2}\right)$. Even the net long wave radiation quantified under bare soil condition is slightly higher than that obtained under vegetated condition $\left(253 \mathrm{MJ} / \mathrm{m}^{2}\right.$ against $\left.221 \mathrm{MJ} / \mathrm{m}^{2}\right)$ probably due to higher soil surface temperature detectable for bare soil. Nonetheless, the vegetated soil associates with a greater amount of energy available for the evaporation processes, quantified by net radiation measurement $\left(\mathrm{R}_{\mathrm{n}}\right): \mathrm{In}$ fact, the net radiation for bare soil is $811 \mathrm{MJ} / \mathrm{m}^{2}$ while for vegetated condition it is $871 \mathrm{MJ} / \mathrm{m}^{2}$.

Net, solar and net long wave radiation allows the quantification of the albedo for the two cover conditions. For bare soil the mean value of albedo retrieved is about 0.36 while for vegetated cover conditions it is about 0.32 . Such values are consistent with those retrievable in literature [26]. Indeed, for its roughness and colour, the vegetated surface is characterized by lower albedo then the bare soil. Under the same solar and long wave radiation, the vegetated soil has therefore a more available energy than the bare soil for the evaporation.

\subsection{Water content variations within the layer}

The major evaporative flows occurring under vegetated conditions due to the plant transpiration turns, as expected, into more pronounced water content reductions throughout the layer.

In this regard, Figure 6 shows the isochrones of water content recorded under bare soil (Figure 6a) and vegetated soil conditions (Figure 6b) measured at several times. 


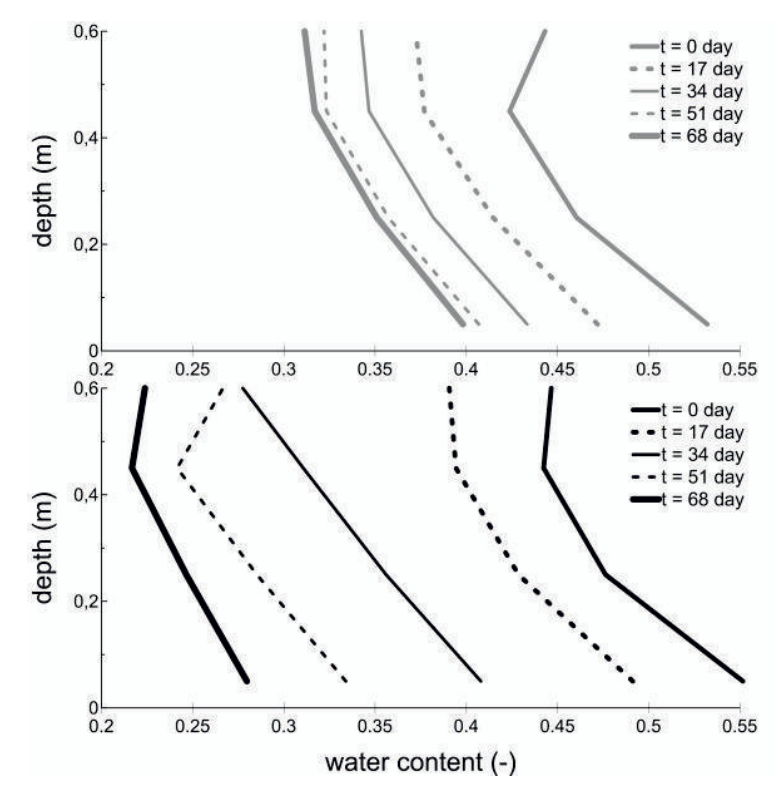

(a)

Figure 6. Isochrones of water content recorded under bare soil (a) and vegetated cover (b) conditions.

The data are related to four depth $(15,30,50$ and $70 \mathrm{~cm})$ within the layer.

In general, the water content isochrones show a rigid translation with a reduction of water content at all depths. Such behaviour is typically exhibited by the layer during the evaporative processes as shown in [14-16].

During the bare soil experiment, moving from water content ranging between 0.45 and 0.55 at $\mathrm{t}=0$ day, the layer reduces at all depths its water content as a consequence of the evaporative process. At $\mathrm{t}=68$ day, the water content is about 0.3 at depth of $15 \mathrm{~cm}$ and about 0.4 at depth of $70 \mathrm{~cm}$.

From an analogue initial distribution of water content, the isochrones monitored under vegetated cover condition exhibit after only 17 days a trend similar to that recorded after 68 days for bare soil case. Under vegetated cover condition, at $\mathrm{t}=68$ day, the evaporative fluxes induce a strong desaturation of the soil layer; at this stage, the water content ranges between 0.22 and 0.27 .

This sharp difference observed in the two experimentations is mainly attributable to the effect of plant transpiration. A rough assessment between final profiles show how in the deeper $60 \mathrm{~cm}$ the differences worth about $65 \mathrm{~mm}(0.11)$; as difference with total value $(89 \mathrm{~mm})$, the spread in the shallower $15 \mathrm{~cm}$ can be estimated as about $24 \mathrm{~mm}(\theta=0.16)$.

These results show how the presence of roots permits pulling out water from the cover in more effective way also from greater depths.

\section{Conclusion}

The works displays the main findings related to the monitoring of a pyroclastic soil volume under two different soil surface conditions during two summer seasons characterized by comparable weather forcing. Focusing on evaporative losses, the summer season allows evaluating in more evident way the different behaviours. Since the results, the added value of vegetated surface clearly arises; however, albeit they are related to summer season, it is reasonable that also in other seasons the vegetation can induce higher evaporative fluxes even if under lower values. In this way, the presence of vegetation on the slopes could contribute to reducing average water content values within the soil and improving slope stability conditions producing "less predisposing conditions" when an heavy rainfall event occur. It represents an issue of great interest for the soils adopted in monitoring, coming from Campanian slopes affected in last years by several landslide events. Furthermore, it should not be omitted that higher evaporative losses represent only one of the beneficial effects of the vegetation on the slope stability acting also with interception in reducing water inputs and providing through roots a further mechanical support for the shallower soil layers.

\section{References}

1. R. C. Sidle, H. Ochiai, Landslides: Processes, Prediction, and Land Use (American Geophysical Union, 2006)

2. EEA (European Environment Agency), A Exploring nature-based solutions: The role of green infrastructure in mitigating the impacts of weatherand climate change-related natural hazards (EEA Technical report No 12/2015, 2015)

3. A. Vallario, Il dissesto idrogeologico (CUEN, 2001)

4. L. Picarelli, A. Santo, G. Di Crescenzo, L. Olivares, X Int. Symp. Land. 2, 1951-1958 (2008)

5. L. Pagano, L. Picarelli, G. Rianna, G. Urciuoli, Landslides 7(3), 273-289 (2010)

6. E. Damiano, L. Olivares, L. Picarelli, Eng. Geol. 137-138, 1-12 (2012)

7. L. Cascini, G. Sorbino, S. Cuomo, S. Ferlisi, Landslides, 11(5), 779-792 (2014)

8. M. Pirone, R. Papa, M. V. Nicotera, G. Urciuoli G, Landslides 12(2), 259-276 (2015)

9. E. Damiano, L. Olivares, Nat. Haz. 52(2), 329-350 (2010)

10. M. V. Nicotera, R. Papa, G. Urciuoli, Geotech. Testing J. 33 (4), 263-285 (2010)

11. F. Rossi, G. B. Chirico, Definizione delle soglie pluviometriche d'allarme (G.N.D.C.I.-C.N.R., Italy, 1998)

12. P. De Vita, V. Piscopo, Nat. Haz. Earth Sys. Sc. 2, 27-35 (2002)

13. G. Di Crescenzo, A. Santo, Geom. 66, 225-276 (2005)

14. G. Rianna, L. Pagano, G. Urciuoli, Eng. Geol. 174, 22-35 (2014)

15. G. Rianna, L. Pagano, G. Urciuoli, J. Hydrol. 510, 480-492 (2014)

16. L. Pagano, A. Reder, G. Rianna, It. Geot. J. 1, 62-76 (2014)

17. L. Pagano, A. Reder, G. Rianna, Proc. Earth Plan. Sc. 9, 14-22 (2014)

18. A. Reder, G. Rianna, L. Pagano, Ad. Env. Geol. Sc. Eng. 273-280 (2014) 
19. M. Pirone, E. Damiano, L. Picarelli, L. Olivares, G. Urciuoli, It. Geot. J. 3, 29-50 (2012)

20. R. Greco, L. Comegna, E. Damiano, A. Guida, L. Olivares, L. Picarelli, Hydrol. Earth Syst. Sci. 17, 4001-4013 (2013)

21. L. Comegna, E. Damiano, R. Greco, A. Guida, L. Olivares, L. Picarelli, Proc. Env. Sc. 19, 922-931 (2013)

22. R. Papa, A. Evangelista, M. V. Nicotera, G. Urciuoli, Proc. E-UNSAT, 917-923 (2008)

23. M. C. Zingariello, Progettazione, messa a punto e primi risultati di un modello fisico di pendio (Phd thesis, Naples, 2006)

24. A. Reder, G. Rianna, L. Pagano, Proc. Earth Plan. Sc. 9, 171-179 (2014)

25. R. G. Allen, L. S. Pereira, D. Raes, M. Smith, FAO Irrigation and Drainage. Paper No. 56: Crop Evapotranspiration (Guidelines for Computing Crop Water Requirements) (1998)

26. T. R. Oke, Boundary Layer Climates (Routledge, 2nd edition, 1987) 